\title{
A BISHOP-PHELPS-BOLLOBÁS TYPE PROPERTY FOR MINIMUM ATTAINING OPERATORS
}

\author{
NEERU BALA AND G. RAMESH
}

\begin{abstract}
In this article, we study the Bishop-Phelps-Bollobás type theorem for minimum attaining operators. More explicitly, if we consider a bounded linear operator $T$ on a Hilbert space $H$ and a unit vector $x_{0} \in H$ such that $\left\|T x_{0}\right\|$ is very close to the minimum modulus of $T$, then $T$ and $x_{0}$ are simultaneously approximated by a minimum attaining operator $S$ on $H$ and a unit vector $y \in H$ for which $\|S y\|$ is equal to the minimum modulus of $S$. Further, we extend this result to a more general class of densely defined closed operators (need not be bounded) in Hilbert space. As a consequence, we get the denseness of the set of minimum attaining operators in the class of densely defined closed operators with respect to the gap metric.
\end{abstract}

Mathematics subject classification (2020): 46A32, 47A55, 47A58, 47L05.

Keywords and phrases: Bishop-Phelps-Bollobás theorem, closed operator, minimum attaining opera-

tors.

\section{REFERENCES}

[1] M. D. Acosta et al., The Bishop-Phelps-Bollobás theorem for operators, J. Funct. Anal. 254 (2008), no. 11, 2780-2799. MR2414220

[2] M. Birman AND M. Z. SOlomjaK, Spectral theory of selfadjoint operators in Hilbert space (Russian), Leningrad. Univ., Leningrad, 1980. MR0609148

[3] L. X. Cheng AND Y. B. Dong, A quantitative version of the Bishop-Phelps theorem for operators in Hilbert spaces, Acta Math. Sin. (Engl. Ser.) 28 (2012), no. 10, 2107-2114. MR2966957

[4] J. B. Conway, A course in operator theory, Graduate Studies in Mathematics, 21, American Mathematical Society, Providence, RI, 2000. MR1721402

[5] J. Ganesh, G. Ramesh And D. Sukumar, Perturbation of minimum attaining operators, Adv. Oper. Theory 3 (2018), no. 3, 473-490. MR3795095

[6] T. Kato, Perturbation theory for linear operators, Die Grundlehren der mathematischen Wissenschaften, Band 132, Springer-Verlag New York, Inc., New York, 1966. MR0203473

[7] S. H. KulKarni AND G. RAMESh, Absolutely minimum attaining closed operators, J Anal (2019), https://doi.org/10.1007/s41478-019-00189-x.

[8] S. H. KULKARNI AND G. RAMESH, A formula for gap between two closed operators, Linear Algebra Appl. 432 (2010), no. 11, 3012-3017. MR2639265

[9] S. H. KUlKARNI AND G. RAMESH, On the denseness of minimum attaining operators, Oper. Matrices 12 (2018), no. 3, 699-709. MR3853362

[10] J. Lindenstrauss, On operators which attain their norm, Israel J. Math. 1 (1963), 139-148. MR0160094

[11] G. RAMESH, The Horn-Li-Merino formula for the gap and the spherical gap of unbounded operators, Proc. Amer. Math. Soc. 139 (2011), no. 3, 1081-1090. MR2745658

[12] W. RUdin, Functional analysis, second edition, International Series in Pure and Applied Mathematics, McGraw-Hill, Inc., New York, 1991. MR1157815

[13] A. E. TAYLOR, The minimum modulus of a linear operator, and its use for estimates in spectral theory, Studia Math. (Ser. Specjalna) Zeszyt 1 (1963), 131-132. MR0152888 